\title{
EQUIVALENCE RESULTS FOR OPTIMAL PASS-THROUGH, OPTIMAL INDEXING TO EXCHANGE RATES, AND OPTIMAL CHOICE OF CURRENCY FOR EXPORT PRICING
}

\author{
Charles Engel \\ University of Wisconsin
}

\begin{abstract}
Firms sometimes write price lists or catalogs for their exports, so they set prices for a period of time and do not adjust prices during that interval in response to changes in their environment. The firm sets the price either in its own currency or the importer's currency. This paper draws a simple link between the choice of currency and the pricing decision of a firm that changes prices in response to all shocks. Specifically, if the latter firm's price has a lower variance in terms of its own currency than the importer's currency, then the firm with a price list will set the price in its own currency (and otherwise it will set price in the foreign currency). This relationship is established by consideration of the firm with a price list as a special case of a firm that indexes its export price to the exchange rate. (JEL: F4, F1)
\end{abstract}

\section{Introduction}

Many exporting firms have price lists or catalogs for their exported products. The price is set for an interval of time and does not respond to changes in the environment (such as changes in demand or production costs) during that period. Firms typically set a price either in their own currency or the importer's currency. An extensive literature has investigated the optimal currency of price setting when prices are sticky in this way. ${ }^{1}$

A related literature examines the optimal export price. In some of the literature, the price is assumed to respond to all shocks that might influence its price. ${ }^{2}$

Acknowledgments: I have benefited from the comments of two referees, as well as Michael Devereux, Rob Feenstra, Akito Matsumoto, Roberto Perotti, and especially Cedric Tille. I have also received helpful comments on earlier versions of this paper from seminars at the Hong Kong Institute for Monetary Research (HKIMR) and the Bank of Italy. I thank the HKIMR and NSF for support for this research.

E-mail addresses: Engel: cengel@ssc.wisc.edu

1. Baron (1976), Giovannini (1988), Donnenfeld and Zilcha (1991), Friberg (1998), Devereux, Engel, and Storgaard (2004), Bacchetta and van Wincoop (2003, 2005), Corsetti and Pesenti (2004), and Goldberg and Tille (2004) are examples.

2. Krugman (1987), Dornbusch (1987), Baldwin (1988), Froot and Klemperer (1989), Marston (1990), Goldberg and Knetter (1999), Goldberg and Verboven (2001), Bergin (2003), Goldberg and Campa (2005), and Corsetti and Dedola (2005) are examples. 
Another strand of the literature assumes that export prices are set for a period of time and examines the factors that influence the price (with the currency of invoicing given, rather than chosen optimally). ${ }^{3}$ Here we draw a link between the literature on currency of price setting and the literature in which firms can choose their price flexibly with knowledge of all shocks. When prices are sticky, the literature uses the terms producer currency pricing (PCP) to denote the case in which prices are set in the producer's currency and local currency pricing (LCP) for the case in which prices are set in the importer's currency. Can a firm making the decision of currency for pricing (PCP vs. LCP) draw on the literature that examines how flexible export prices respond optimally to exchange rates?

Hypothetically, firms that set prices in advance might be able to index their price to the exchange rate. Consider a firm that is constrained to choose the parameters $p_{0}$ and $\beta$ so that the log of its price is indexed to the exchange rate by the function $p_{0}+\beta s$, where $s$ is the log of the exchange rate (expressed as the exporting country's price of the importer's currency.) Let $\hat{\beta}$ be the optimal choice of $\beta{ }^{4}$

If firms must choose PCP or LCP, they face a constrained version of the indexing problem, where they must choose either $\beta=-1$ (PCP) or $\beta=0$ (LCP). If we take a quadratic approximation to the firm's objective function, it follows (as demonstrated subsequently) that firms that are constrained to choose PCP or LCP will pick PCP when $\hat{\beta}<-0.5$, and LCP when $\hat{\beta}>-0.5$.

We also show that (under the quadratic approximation to the firm's objective function) $\hat{\beta}$ can be determined simply by a linear projection of the log of the firm's optimal price under flexible prices ( $\hat{p}^{*}$ in foreign currency terms) on the log of the exchange rate, $s: \hat{\beta}=\operatorname{cov}\left(\hat{p}^{*}, s\right) / \operatorname{var}(s)$. The right-hand side of this equation is an "unconditional pass-through elasticity." It is the (population) regression coefficient of the log of the import price on the log of the exchange rate.

Our main theorem then follows from these two results. It says that if prices are sticky, firms choose PCP precisely when $\hat{\beta}<-0.5$, and LCP when $\hat{\beta}>-0.5$. That is, firms that must set prices in advance will choose to price in their own currency (so that ex post there is $100 \%$ pass-through) exactly when their prices would exhibit high (unconditional) pass-through if they were set flexibly, and they choose LCP (zero ex post pass-through) exactly when their prices would display

3. Examples include Feenstra (1989), Feenstra and Kendall (1997), Bacchetta and van Wincoop (2000), Obstfeld and Rogoff (2002), Bergin and Feenstra (2001), and Corsetti and Pesenti (2005).

4. Corsetti and Pesenti (2005) build a general equilibrium model in which firms index to exchange rates, but the degree of indexation is taken as given. Corsetti and Pesenti (2004) and Goldberg and Tille (2004) build models in which the degree of indexation is chosen optimally. Tille's note to me linking an earlier version of this paper to Goldberg and Tille is what led me to the lemma described here. Tille's note shows that the relationship in the lemma holds in the model of Goldberg and Tille. 
low (unconditional) pass-through under flexible prices. ${ }^{5}$ It might be helpful to see that the condition $\hat{\beta}<-0.5$ is equivalent to $\operatorname{var}(\hat{p})<\operatorname{var}\left(\hat{p}^{*}\right)$, where $\hat{p}$ is the $\log$ of the firm's optimal price expressed in its own currency $\left(\hat{p}=\hat{p}^{*}+s\right)$.

The theorem clarifies the link between the literature on pass-through, and the literature on currency of pricing. The main theorem establishes a dual approach that gives a more convenient way to look at conditions for PCP or LCP. This might simplify the reading of the literature and might also have practical implications for firms that are choosing a currency for invoicing.

The main theorem also provides a caution in interpreting empirical work on the relationship between exchange rates and prices. The theorem suggests that without further refinement, finding that prices do not respond much to exchange rates is difficult to interpret either as support or contradiction for the notion that nominal prices are "sticky." This warning cuts both ways. Export prices may respond very little to exchange rate changes even when firms are free to adjust their prices continuously. The same conditions under which firms choose LCP tell us that import prices are not very responsive to exchange rates even if they are set flexibly. Conversely, empirical confirmation of models that imply low passthrough under flexible prices could also be interpreted as evidence of LCP. For example, some recent studies have found support for models of firms with freely adjustable prices in which local distribution services are an important part of the cost of exported goods. ${ }^{6}$ The studies conclude that the local-currency stability of the price of these distribution services is a major explanation for local currency stability of export prices. Our theorem says that under these same conditions, if export prices cannot be adjusted in response to shocks, they should be set in the local-currency price. Without a more detailed study of the adjustment of prices to distinguish the two types of models, the evidence could be consistent with either flexible or sticky prices. ${ }^{7}$

\section{Models of Export Pricing}

We consider the price-setting decision for a monopolistic firm that sells in a single foreign market. First we take the case in which the firm can choose the price for its product with full information about demand, costs, and so forth. We call that firm a flexible-price setter.

5. This result is demonstrated using a second-order approximation of the firm's objective function under uncertainty. Friberg (1998) also links the invoicing literature to the price-setting literature. This paper generalizes Friberg's result in a way that is clarified below.

6. For example, Goldberg and Verboven (2001), Burstein, Neves, and Rebelo (2003), Burstein, Eichenbaum, and Rebelo (2002), and Goldberg and Campa (2005).

7. Examples of empirical studies that have explicitly allowed for both slow nominal price adjustment and incomplete long-run pass-through are Marston (1990) and Goldberg and Verboven (2005). 
We assume that the firm maximizes discounted profits but that the discount factor $D$ is exogenous for the firm—not a function of the firm's price. If the firm is simply maximizing real profits (in terms of purchasing power of the firm's owners), then $D$ is the inverse of the consumer price index for the firm's owners. If firm owners are risk-averse, $D$ could be the marginal utility of an increment to profit denominated in the currency of the exporter. This objective for the firm holds under a variety of possible assumptions about the objectives of the firm managers, the structure of asset markets, and possibilities for hedging. The assumption that $D$ is exogenous to the firm does rule out some possibilities, however. Suppose a single household owns the firm and the owner-manager discounts profits by marginal utility. The outcome for the firm might directly affect the level of consumption of the owner, and thus the marginal utility. The assumption that $D$ is exogenous to the firm would be violated. An exogenous discount factor is more sensible when, for example, there are many owners of the firm, and there are many other sources of income for each owner. Thus our assumption of an exogenous discount factor is violated in the models of Feenstra and Kendall (1997) and the model of risk-averse firm owners in Friberg (1998), who assume in essence that firm owners' only income is from profits (so that the firm maximizes the expected utility of profits.)

In the flexible price case, the discount factor is simply a constant that multiplies profits and does not affect the optimal choice of price (given the assumption that the choice of price does not affect $D$.) The firm then chooses $p^{*}$, the $\log$ of the foreign currency price of its export to maximize the twice-differentiable concave profit function $\pi\left(p^{*}, \mathbf{x}\right)$. $\mathbf{x}$ is a vector of variables that affect the firm's profits but are exogenous to the firm. This vector might include the exchange rate.

The first-order condition is

$$
\pi_{p}\left(p^{*}, \mathbf{x}\right)=0 .
$$

We want to linearize this function around $\mathbf{x}=\overline{\mathbf{x}}$, where $\overline{\mathbf{x}}$ is the mean of $\mathbf{x}$, and $p^{*}=\tilde{p}^{*}$, where $\tilde{p}^{*}$ is the value of $p^{*}$ that satisfies $\pi_{p}\left(\tilde{p}^{*}, \overline{\mathbf{x}}\right)=0$. We get

$$
\pi_{p p}\left(\tilde{p}^{*}, \overline{\mathbf{x}}\right) \cdot\left(p^{*}-\tilde{p}^{*}\right)+\pi_{p x}\left(\tilde{p}^{*}, \overline{\mathbf{x}}\right)^{\prime} \cdot(\mathbf{x}-\overline{\mathbf{x}})=0,
$$

where $\pi_{p x}\left(\tilde{p}^{*}, \overline{\mathbf{x}}\right)$ is a vector whose $i$ th element is $\partial^{2} \pi\left(p^{*}, \mathbf{x}\right) / \partial p^{*} \partial x_{i}$. Alternatively, equation (2) is the first-order condition for choosing $p^{*}$ to maximize a second-order approximation (around $\mathbf{x}$ and $\tilde{p}^{*}$ ) of the objective function. ${ }^{8}$

Solving (2), we get:

$$
\hat{p}^{*}=\tilde{p}^{*}-\frac{\pi_{p x}^{\prime}\left(\tilde{p}^{*}, \overline{\mathbf{x}}\right)}{\pi_{p p}\left(\tilde{p}^{*}, \overline{\mathbf{x}}\right)} \cdot(\mathbf{x}-\overline{\mathbf{x}}),
$$

8. Specifically, the second-order approximation (using $\pi_{p}\left(p^{*}, \mathbf{x}\right)=0$ ) is given by $\pi\left(p^{*}, \mathbf{x}\right) \approx$ $\pi\left(\tilde{p}^{*}, \overline{\mathbf{x}}\right)+\pi_{x}\left(\tilde{p}^{*}, \overline{\mathbf{x}}\right)^{\prime}(\mathbf{x}-\overline{\mathbf{x}})+0.5\left\{\pi_{p p}\left(\tilde{p}^{*}, \overline{\mathbf{x}}\right)\left(p^{*}-\tilde{p}^{*}\right)^{2}+(\mathbf{x}-\overline{\mathbf{x}})^{\prime} \pi_{x x}\left(\tilde{p}^{*}, \overline{\mathbf{x}}\right)(\mathbf{x}-\overline{\mathbf{x}})+2\left(p^{*}-\right.\right.$ $\left.\left.\tilde{p}^{*}\right) \pi_{p x}\left(\tilde{p}^{*}, \overline{\mathbf{x}}\right)^{\prime}(\mathbf{x}-\overline{\mathbf{x}})\right\}$. 
where $\hat{p}^{*}$ is the optimal value of $p^{*}$ for this firm. The unconditional pass-through elasticity - the coefficient in the projection of $\hat{p}^{*}$ on $s$ (the log of the exchange rate expressed as the home currency price of foreign currency)—satisfies

$$
b_{p^{*} s}=\frac{-\pi_{p x}^{\prime}\left(\tilde{p}^{*}, \overline{\mathbf{x}}\right)}{\pi_{p p}\left(\tilde{p}^{*}, \overline{\mathbf{x}}\right)} \cdot \mathbf{b}_{x s},
$$

where the $i$ th element of the vector $\mathbf{b}_{x s}$ is equal to the coefficient in the projection of $x_{i}$ on $s$.

Now set aside this case in which the firm can set its price with knowledge of all the components of $\mathbf{x}$ and turn to the case in which the firm must set its price without knowledge of any components of $\mathbf{x}$. Suppose, though, that the firm can commit to setting $p^{*}$ as an affine function of $s: p^{*}=p_{0}+\beta s$. The firm is assumed to maximize a second-order approximation of the profit function, discounting profits by the factor $D$. The expansion is around $\bar{D}$ (the mean of $D$ ), and $\overline{\mathbf{x}}$ and $\tilde{p}^{*}$ defined previously:

$$
\begin{aligned}
E D \pi\left(p^{*}, \mathbf{x}\right) \approx & \bar{D} \pi\left(\tilde{p}^{*}, \overline{\mathbf{x}}\right)+\pi\left(\tilde{p}^{*}, \overline{\mathbf{x}}\right) E(D-\bar{D}) \\
+ & \bar{D} \pi_{p}\left(\tilde{p}^{*}, \overline{\mathbf{x}}\right) E\left(p^{*}-\tilde{p}^{*}\right)+\bar{D} \pi_{x}\left(\tilde{p}^{*}, \overline{\mathbf{x}}\right)^{\prime} E(\mathbf{x}-\overline{\mathbf{x}}) \\
+ & 0.5\left\{\bar{D} \pi_{p p}\left(\tilde{p}^{*}, \overline{\mathbf{x}}\right) E\left(p^{*}-\tilde{p}^{*}\right)^{2}+\bar{D} E(\mathbf{x}-\overline{\mathbf{x}})^{\prime} \pi_{x x}\left(\tilde{p}^{*}, \overline{\mathbf{x}}\right)(\mathbf{x}-\overline{\mathbf{x}})\right. \\
& \left.+2 \bar{D} E\left(p^{*}-\tilde{p}^{*}\right) \pi_{p x}\left(\tilde{p}^{*}, \overline{\mathbf{x}}\right)^{\prime}(\mathbf{x}-\overline{\mathbf{x}})\right\} .
\end{aligned}
$$

$\pi_{x x}\left(\tilde{p}^{*}, \overline{\mathbf{x}}\right)$ is a matrix whose $i j$ th element is $\partial^{2} \pi\left(p^{*}, \mathbf{x}\right) / \partial x_{i} \partial x_{j}$. All of the firstorder terms in this expansion drop out, because $E(D-\bar{D})=0, E(\mathbf{x}-\overline{\mathbf{x}})=\mathbf{0}$, and $\pi_{p}\left(\tilde{p}^{*}, \overline{\mathbf{x}}\right)=0$. Simplifying, dropping the constant term, and then dropping $\bar{D}$ which multiplies all remaining terms, we can write the objective as

$$
\begin{aligned}
& \pi_{p p}\left(\tilde{p}^{*}, \overline{\mathbf{x}}\right) E\left(p^{*}-\tilde{p}^{*}\right)^{2}+E(\mathbf{x}-\overline{\mathbf{x}})^{\prime} \pi_{x x}\left(\tilde{p}^{*}, \overline{\mathbf{x}}\right)(\mathbf{x}-\overline{\mathbf{x}}) \\
& \quad+2 E\left(p^{*}-\tilde{p}^{*}\right) \pi_{p x}\left(\tilde{p}^{*}, \overline{\mathbf{x}}\right)^{\prime}(\mathbf{x}-\overline{\mathbf{x}}) .
\end{aligned}
$$

Notice that the discount factor has completely disappeared from the approximated objective function. This occurs because of the assumption that $D$ is exogenous for the firm.

Replacing $p^{*}$ with $p_{0}+\beta s$, we find the first-order conditions for choosing $p_{0}$ and $\beta$, respectively:

$$
\begin{gathered}
\pi_{p p}\left(\tilde{p}^{*}, \overline{\mathbf{x}}\right) E\left(p_{0}+\hat{\beta} s-\tilde{p}^{*}\right)=0, \\
\pi_{p p}\left(\tilde{p}^{*}, \overline{\mathbf{x}}\right) E s\left(p_{0}+\hat{\beta} s-\tilde{p}^{*}\right)+\pi_{p x}\left(\tilde{p}^{*}, \overline{\mathbf{x}}\right)^{\prime} E s(\mathbf{x}-\overline{\mathbf{x}})=0,
\end{gathered}
$$

where $\hat{\beta}$ is the value of $\beta$ that maximizes the objective. From the first condition, we have $p_{0}=-\hat{\beta} \bar{s}+\tilde{p}^{*}$. Substitute into the second condition to obtain

$$
\hat{\beta} \pi_{p p}\left(\tilde{p}^{*}, \overline{\mathbf{x}}\right) E s(s-\bar{s})+\pi_{p x}\left(\tilde{p}^{*}, \overline{\mathbf{x}}\right)^{\prime} E s(\mathbf{x}-\overline{\mathbf{x}})=0 .
$$

$$
\text { “zwu005060392” — 2006/10/20 — page } 1253 \text { - \#5 }
$$


Solving for $\hat{\beta}$, we find

$$
\hat{\beta}=\frac{-\pi_{p x}^{\prime}\left(\tilde{p}^{*}, \overline{\mathbf{x}}\right)}{\pi_{p p}\left(\tilde{p}^{*}, \overline{\mathbf{x}}\right)} \cdot \frac{\operatorname{cov}(s, \mathbf{x})}{\operatorname{var}(s)} .
$$

Comparison of equations (4) and (6) immediately gives us the following lemma.

LEMMA 1. Under the quadratic approximation to the objective functions, the unconditional pass-through elasticity when prices are set flexibly, $b_{p^{*}}$, equals the exchange-rate elasticity of the import price index, $\hat{\beta}$.

Intuitively, a firm that can commit to set the log of the price as a linear function of the log of the exchange rate operates exactly like a firm that can observe the exchange rate when setting its price. If that firm can observe only $s$, and not other elements of $\mathbf{x}$, then it will form its optimal linear forecast of $\hat{p}^{*}$ by taking the projection of $\hat{p}^{*}$ on $s$. Thus, the indexing firm in essence is a flexible-price firm that must set $\hat{p}^{*}$ as a linear function of $s$ and nothing else.

We can now consider the more realistic case of a sticky-price firm that must set a price for export either in its own currency or the currency of the importer. This firm can be thought of as choosing an index function, $p_{0}+\beta s$, but with only two choices of $\beta, 0$ or -1 . If $\beta=0$, the export price is constant in the foreign currency, so the firm is LCP. If $\beta=-1$, the price is constant in the producer's currency, so the firm is PCP.

The main theorem draws a link between the choice facing this firm and the firm that can set prices flexibly with full knowledge of $\mathbf{x}$.

THEOREM 1. Under the quadratic approximation to the firm's objective function, when a firm must set its price in advance and choose between LCP or $P C P$, it chooses LCP exactly when the unconditional pass-through elasticity for the flexible-price firm is less than one-half in absolute value $\left(b_{p^{*}}>-0.5\right)$. Likewise, the firm that sets price in advance chooses PCP if and only if the unconditional pass-through elasticity for the flexible-price firm is greater than one-half in absolute value $\left(b_{p^{*} s}<-0.5\right)$.

Proof. The objective function of the firm that sets price in advance is continuous in $\beta$. Because the function is quadratic, it is symmetric around its unique maximum point, $\hat{\beta}$, given in equation (6). Because the quadratic function is continuous, strictly concave and symmetric, the value of the objective function is higher for $\beta=0$ than for $\beta=-1$ (so LCP is preferred) when $\hat{\beta}>-0.5$, and PCP is preferred when $\hat{\beta}<-0.5$.

But if $\hat{\beta}>-0.5$, then, from Lemma $1, b_{p^{*} s}>-0.5$.

Because $\hat{\beta}>-0.5$ is equivalent to $\operatorname{var}\left(\hat{p}^{*}\right)<\operatorname{var}(\hat{p})$, an alternative interpretation of the theorem is that with sticky prices firms choose LCP under the 
same conditions that the flexible-price firm's price would have a lower variance when expressed in the importer's currency than the exporter's currency.

\section{Discussion}

Here we consider an example that encompasses a lot of the literature on passthrough and the choice of currency for price setting. ${ }^{9}$

Consider a firm that faces a demand curve $Y^{D}=G\left(P^{*} / Z\right) N$. $P^{*}$ is the foreign-currency price of the firm's product, $Z$ is a price index of products that are substitutes for our firm's product, and $N$ represents other factors that shift demand. We assume that the product is produced using two variable inputs: one local and one foreign. The local input might be labor used to produce the product, and the foreign input might be foreign labor used to distribute the product, or to assemble imported intermediate goods into final products. The cost function takes the form $C(Y) \cdot H\left(W_{1}, S W_{2}^{*}\right)$, where $C^{\prime}>0$ and $C^{\prime \prime}$ may be positive or negative. ${ }^{10} Y$ refers to output for the firm. We assume $H(\cdots)$ is homogeneous of degree $1 . W_{1}$ is the home-currency nominal unit factor costs for the home input. $W_{2}^{*}$ is the cost of the foreign-currency price of the foreign input. $S$ is the home currency cost of foreign currency.

Application of equation (3) in this case yields

$$
p^{*}=\frac{\varepsilon+\delta \gamma(\gamma-1)}{\Delta} z+\frac{\delta(\gamma-1)}{\Delta} n+\frac{\omega(\gamma-1)}{\Delta}\left(w_{1}-s\right)+\frac{(1-\omega)(\gamma-1)}{\Delta} w_{2}^{*},
$$

where lower-case letters are the logs of their upper-case counterparts. Here, we have $\gamma \equiv-P^{*} G^{\prime} / Z G$ (the elasticity of demand for the product), $\varepsilon \equiv P^{*} \gamma^{\prime} / Z \gamma$ (the elasticity of the elasticity of demand), $\delta \equiv C^{\prime \prime} Y / C^{\prime}$ (a measure of concavity or convexity of the cost function), $\omega \equiv H_{1} W_{1} / H$ (factor 1's share of costs), and $\Delta \equiv \gamma-1+\varepsilon+\delta \gamma(\gamma-1){ }^{11}$

We have from this equation that $b_{p^{*}}$ is given by

$$
\begin{aligned}
b_{p^{*} s}= & \frac{\varepsilon+\delta \gamma(\gamma-1)}{\Delta} b_{z s}+\frac{\delta(\gamma-1)}{\Delta} b_{n s} \\
& +\frac{\omega(\gamma-1)}{\Delta} b_{w_{1} s}+\frac{(1-\omega)(\gamma-1)}{\Delta} b_{w_{2}^{*} s}-\frac{\omega(\gamma-1)}{\Delta} .
\end{aligned}
$$

9. This example is worked out in great detail in an earlier draft of this paper, Engel (2003).

10. There is a second-order conditions for a maximum to be satisfied (see subsequent discussion).

11. $\Delta>0$ by the second-order condition for profit maximization. 
It follows that PCP is optimal when

$$
\begin{aligned}
{[\varepsilon+} & \delta \gamma(\gamma-1)] b_{z s}+\delta(\gamma-1) b_{n s}+\omega(\gamma-1) b_{w_{1} s}+(1-\omega)(\gamma-1) b_{w_{2}^{*} s} \\
& <\frac{(2 \omega-1)(\gamma-1)-\varepsilon-\delta \gamma(\gamma-1)}{2} .
\end{aligned}
$$

This example can be related to some of the literature on optimal currency of pricing:

The necessary and sufficient condition derived in Devereux, Engel, and Storgaard (2004) for PCP pricing is a special case of this condition when $\varepsilon=0$ (so demand is constant elasticity), $\delta=0$ (so the cost function is linear in output), $\omega=1$ (so only local inputs are used), and $\gamma>1$. In that case, the condition reduces to $b_{w_{1} s}<0.5$ (which corresponds to their Proposition 1).

The simple example behind Proposition 1 of the partial equilibrium model of Bacchetta and van Wincoop (2005) is also a special case, when the exchange rate is the only stochastic variable, $\varepsilon=0, \omega=1$, and $\gamma>1$. In that case, equation (8) becomes $\delta \gamma<1$ (which corresponds to their Theorem 1). The condition for PCP pricing in Bachetta and van Wincoop's more general model can also be interpreted as a special case of equation (8). That model allows for the price of competing goods to covary with the exchange rate-that is, $b_{z s} \neq 0$, but still maintains $\varepsilon=0, \omega=1$, and $\gamma>1$. Under these assumptions, equation (8) reduces to $\delta \gamma\left(1+2 b_{z s}\right)<1$.

Bacchetta and van Wincoop (2003) consider a model in which there are two stages of production: Exporters sell intermediate goods to final producers, who in turn sell to consumers. If the final producers are LCP, then the exporting firm's problem is a special case of the one considered here in which the only stochastic variable is the exchange rate, $\varepsilon=0, \omega=1$, and $\gamma>1$. (The input for exporters is the wage in the exporting country, and $Z$ is the price of final goods. $Z$ is nonstochastic when final goods producers follow LCP.) The condition for the exporter to price in its own currency is then the special case of equation (8) given by $\delta_{I} \gamma_{I}<1$ (as in their Theorem 1), where $\delta_{I}$ measures the curvature of the exporting firm's production function and $\gamma_{I}$ is the elasticity of demand faced by exporters. If the exporters are PCP, then the final goods producers also have a problem that is the same special case. The input price is the price of the exported good, which is priced in the exporter's currency (so $\omega=1$ ), and only the exchange rate is stochastic. The condition for LCP pricing is a special case of equation (8): $\delta_{F} \gamma_{F}>1$ (as in their Theorem 2), but now $\delta_{F}$ relates to the final goods producers' technology, and $\gamma_{F}$ is the elasticity of demand of final goods consumers. Bacchetta and van Wincoop then conclude there is a Nash equilibrium in which exporters play PCP and final goods producers play LCP if $\delta_{I} \gamma_{I}<1$ and $\delta_{F} \gamma_{F}>1$.

$$
\text { “zwu005060392” — 2006/10/20 — page } 1256 \text { — \#8 }
$$


Giovannini's (1988) model is the special case in which the exchange rate is the only random variable (so the entire left-hand side of the inequality in equation (8) is zero) and $\omega=1$. In that case, the condition for PCP pricing reduces to $(1-\delta \gamma)(\gamma-1)-\varepsilon>0$, which is precisely the condition that the profit function is convex in the exchange rate.

Friberg (1998), as this paper, compares pass-through under flexible prices to conditions for PCP versus LCP when nominal prices are set in advance. He, like Giovannini (1988), considers the special case in which the exchange rate is the only random variable and $\omega=1$. In this case, in the flexible price model, we have $-b_{p^{*} s}=(\gamma-1) /(\gamma-1+\varepsilon+\delta \gamma(\gamma-1))$.

Because Friberg assumes $\gamma>1$ and $\delta>0$, a sufficient condition for the pass-through coefficient $\left(-b_{p^{*} s}\right)$ to be less than one is $\varepsilon>0$. An even stronger condition is $\varepsilon>\gamma$. Turning to the sticky-price models, under Friberg's assumptions, the condition for firms to choose LCP pricing is

$$
(1-\delta \gamma)(\gamma-1)-\varepsilon<0 .
$$

This condition is met when $\varepsilon>\gamma$. This is Friberg's theorem: that, when $\delta>0$ (and in the confines of his set-up in which the exchange rate is the only random variable and $\omega=1$ ), a sufficient condition for both LCP pricing and a passthrough coefficient less than one is $\varepsilon>\gamma$.

Corsetti and Pesenti (2005) solve the optimal indexing problem for a firm (embedded in a general equilibrium model) with a linear cost function and constant elasticity of demand. The coefficient that indexes the log of the import price to the log of the exchange rate can be determined from equation (7) in this case, with $\varepsilon=0, \delta=0, \omega=1$, and $\gamma>1: \hat{\beta}=b_{p^{*} s}=b_{w_{1} s}-1$.

Finally, note the role of distribution costs incurred in the importing country. If prices are set with full information about the exogenous variables affecting profits, then when distribution costs are a large share of total costs (when $1-$ $\omega$ is close to one) there will be a large elasticity of $p *$ with respect to $w_{2}^{*}$. If wages are very stable (have low variance and therefore a low covariance with the exchange rate) and $\omega$ is close to zero, then the import price will tend to be stabilized in the importer's currency. That is the result noted by, for example, Goldberg and Verboven (2001), Burstein, Neves, and Rebelo (2003), Burstein, Eichenbaum, and Rebelo (2002), and Goldberg and Campa (2005). That result says that, if distribution costs are significant and those costs are relatively stable in the importer's currency, then the apparent pass-through of the exchange rate to the final goods price will be low.

However, under these same conditions, LCP will be optimal. That is, when distribution costs are a large share of total costs and when the wage in the importing cost is stable, it is optimal for the exporting firm to set the price in the consumer's currency. 
To elaborate on this condition, consider the case in which the production function is CES, so that

$$
H\left(W_{1}, S W_{2}^{*}\right)=\left(\lambda W_{1}^{1-\alpha}+(1-\lambda)\left(S W_{2}^{*}\right)^{1-\alpha}\right)^{\frac{1}{1-\alpha}} .
$$

Then we have

$$
1-\omega=\frac{(1-\lambda)\left(S W_{2}^{*}\right)^{1-\alpha}}{\lambda W_{1}^{1-\alpha}+(1-\lambda)\left(S W_{2}^{*}\right)^{1-\alpha}} .
$$

In the Cobb-Douglas case $(\alpha=1)$, we have $1-\omega=1-\lambda$. In that case, the unconditional pass-through is lower the larger the share $1-\lambda$ of foreign inputs into the production process. That is also the case, as the theorem states, in which LCP is more likely. When foreign and domestic inputs are combined in fixed proportions (as in the model of Burstein, Eichenbaum and Rebelo (2002) in which labor in the importing country is used to distribute the good), we find

$$
1-\omega=\left((1-\lambda) S W_{2}^{*}\right) /\left(\lambda W_{1}+(1-\lambda) S W_{2}^{*}\right) .
$$

Under flexible prices, pass-through will be low when the cost of distribution services is high and $1-\lambda$ is large, but again those are also the circumstances in which the exporter that invoices prefers LCP.

Equation (8) is a general statement of a standard model of pass-through in the international trade literature, and suggests empirically testable propositions. Pass-through should be high when equation (8) is satisfied, and low otherwise. But empirical evidence of this link - that, for example, pass-through is low when the distribution share is high, or when demand becomes more elastic at higher prices $(\varepsilon>0)$-does not distinguish whether the flexible-nominal-price model or the sticky-nominal-price approach is appropriate for macroeconomic modeling. The theorem of this paper shows that both types of models imply high pass-through when the condition of equation (7) is met, and low pass-through when it is not. The work cited previously finding a link between high distribution shares and low pass-through, or the studies cited in Goldberg and Knetter (1997) uncovering a link between variable elasticity of demand and pass-through, ${ }^{12}$ do not help us draw inferences about the applicability of flexible-price versus sticky-price models of import pricing.

It is worth noting a few precautions in interpreting these results. First, all of this discussion pertains to the behavior or a single firm taking the economy as given. Some of the papers mentioned cast the firm in a general equilibrium context, but condition (8) takes the vector of regression coefficients, $\mathbf{b}_{x s}$, as given to the firm. In general equilibrium, these are endogenous. Second, these results are

12. For example Aw (1993) and Goldberg and Knetter (1997) find such links. 
derived for a second-order approximation to the profit function. In some instances, third or fourth moments may not be small.

An obvious limit to the model presented here is that it is static. The intuition of the result of this paper is that firms prefer to invoice in the importer's currency when unconditional pass-through is low under price flexibility. But a fuller dynamic analysis would be required to determine the degree to which sluggish price adjustment contributes to local currency stability of import prices. ${ }^{13}$

\section{References}

Aw, Bee-Yan (1993). "Price Discrimination and Markups in Export Markets." Journal of Development Economics, 42, 315-336.

Bacchetta, Philippe, and Eric van Wincoop (2000). "Does Exchange-Rate Stability Increase Trade and Welfare?" American Economic Review, 90, 1093-1109.

Bacchetta, Philippe, and Eric van Wincoop (2003). "Why Do Consumer Prices React Less Than Import Prices to Exchange Rates?" Journal of the European Economics Association, $1,662-670$

Bacchetta, Philippe, and Eric van Wincoop (2005). "A Theory of the Currency Denomination of International Trade." Journal of International Economics, 67, 295-319.

Baldwin, Richard (1988). "Hysteresis in Import Prices: The Beachhead Effect." American Economic Review, 78, 773-385.

Baron, David P. (1976). "Fluctuating Exchange Rates and the Pricing of Exports." Economic Inquiry, 14, 425-438.

Bergin, Paul R. (2003). "A Model of Relative National Price Levels under Pricing to Market." European Economic Review, 47, 569-586.

Bergin, Paul R., and Robert C. Feenstra (2001). "Pricing-to-Market, Staggered Contracts, and Real Exchange Rate Persistence." Journal of International Economics, 54, 333-359.

Burstein, Ariel, Martin Eichenbaum, and Sergio Rebelo (2002). "Why Is Inflation So Low after Large Devaluations?" National Bureau of Economic Research. Working Paper No. 8748.

Burstein, Ariel, Joao Neves, and Sergio Rebelo (2003). "Distribution Costs and Real Exchange Rate Dynamics." Journal of Monetary Economics, 50, 1189-1214.

Choudhri, Ehsan U., Hamid Faruqee, and Dalia S. Hakura (2005). "Explaining the Exchange Rate Pass-Through in Different Prices." Journal of International Economics, 65, 349-374.

Corsetti, Giancarlo, and Luca Dedola (2005). "A Macroeconomic Model of International Price Discrimination.” Journal of International Economics, 67, 129-155.

Corsetti, Giancarlo, and Paolo Pesenti (2004). "Endogenous Pass-Through and Optimal Monetary Policy: A Model of Self-Validating Exchange Rate Regimes." Manuscript, European University Institute.

Corsetti, Giancarlo, and Paolo Pesenti (2005). "International Dimensions of Optimal Monetary Policy." Journal of Monetary Economics, 52, 281-305.

Devereux, Michael B., Charles Engel, and Peter E. Storgaard (2004). "Endogenous Exchange Rate Pass-Through when Nominal Prices Are Set in Advance." Journal of International Economics, 63, 263-291.

Devereux, Michael B., and James Yetman (2005). "Price Adjustment and Exchange Rate PassThrough.” Manuscript, University of Hong Kong.

13. See Marston (1990), Goldberg and Verboven (2005), Choudhri, Faruquce, and Hakura (2005), and Devereux and Yetman (2005). 
Donnenfeld, S., and I. Zilcha (1991). "Pricing of Exports and Exchange Rate Uncertainty." International Economic Review, 32, 1099-1022.

Dornbusch, Rudinger (1987). "Exchange Rates and Prices." American Economic Review, 77, 93-106.

Engel, Charles (2003). "On the Relationship between Pass-Through and Sticky Nominal Prices." Manuscript, University of Wisconsin.

Feenstra, Robert C. (1989). "Symmetric Pass-Through of Tariffs and Exchange Rates under Imperfect Competition: An Empirical Test." Journal of International Economics, 27, 25-45.

Feenstra, Robert C., and Jon D. Kendall (1997). "Pass-Through of Exchange Rates and Purchasing Power Parity.” Journal of International Economics, 43, 237-261.

Friberg, Richard (1998). "In Which Currency Should Exporters Set Their Prices?" Journal of International Economics, 45, 59-76.

Froot, Kenneth A., and Paul D. Klemperer (1989). "Exchange Rate Pass-Through when Market Share Matters." American Economic Review, 79, 637-654.

Giovannini, Alberto (1988). "Exchange Rates and Traded Goods Prices." Journal of International Economics, 24, 45-68.

Goldberg, Linda S., and José M. Campa (2005). "Distribution Margins, Imported Inputs, and the Insensitivity of the CPI to Exchange Rates." Manuscript, Federal Reserve Bank of New York.

Goldberg, Linda S., and Cédric Tille (2004). "Vehicle Currency Use in International Trade." Manuscript, Federal Reserve Bank of New York.

Goldberg, Pinelopi K., and Michael M. Knetter (1997). "Goods Prices and Exchange Rates: What Have We Learned?” Journal of Economic Literature, 35, 1243-1272.

Goldberg, Pinelopi K., and Michael M. Knetter (1999). "Measuring the Intensity of Competition in Export Markets." Journal of International Economics, 47, 27-60.

Goldberg, Pinelopi K., and Frank Verboven (2001). "The Evolution of Price Dispersion in the European Car Market." Review of Economic Studies, 68, 811-848.

Goldberg, Pinelopi K., and Frank Verboven (2005). "Market Integration and Convergence to the Law of One Price: Evidence from the European Car Market." Journal of International Economics, 65, 49-73.

Krugman, Paul (1987). "Pricing to Market when the Exchange Rate Changes." In RealFinanical Linkages among Open Economies, edited by S. W. Arndt and J. D. Richardson. MIT Press, Cambrdige, MA.

Marston, Richard (1990). "Pricing to Market in Japanese Manufacturing." Journal of International Economics, 29, 216-236.

Obstfeld, Maurice, and Kenneth Rogoff (2002). "Risk and Exchange Rates.” In Contemporary Economic Policy: Essays in Honor of Assaf Razin, edited by Elhanan Helpman and Effraim Sadka. Cambridge University Press. 